\title{
Evaluation of polymerization shrinkage of bulk-fill resin composites using microcomputed tomography
}

\author{
Ersen, Kadriye Aybüke ; Gürbüz, Òzge ; Özcan, Mutlu
}

\begin{abstract}
OBJECTIVES This study evaluated the influence of cavity depth on polymerization shrinkage of bulkfill resin composites with and without adhesive resin. MATERIALS AND METHODS Standardized box-shaped cavities (width, $4 \mathrm{~mm}$; length, $5 \mathrm{~mm}$, depth, $2 \mathrm{~mm}$ or $4 \mathrm{~mm}$ ) were made on occlusal surfaces of extracted human third molars $(\mathrm{N}=60)$. The teeth were assigned to 3 groups to receive bulk-fill resin composites (low-viscosity bulk-fill, SDR; high-viscosity bulk-fill; Filtek Bulk-Fill-FB; and TetricEvo Ceram Bulk-Fill-TB) in the prepared cavities with and without adhesive resin (Clearfil S3 Bond). Each specimen ( $n=5$ per group) was scanned twice using microcomputed tomography (micro-CT): once after application of the resin composite to the cavity prior to polymerisation and once after polymerisation. The shrinkage of volumetric loss (\%) was measured using microCT. Data were analysed using Kruskal-Wallis and Mann-Whitney U tests (alpha $=0.05)$. RESULTS The material type $(\mathrm{p}<0.05)$, application of adhesive resin $(\mathrm{p}<0.05)$ and cavity depth $(\mathrm{p}<0.05)$ significantly affected the shrinkage values. The interaction terms were also significant $(\mathrm{p}<0.05)$. All the bulk-fill resin composites tested showed significantly less shrinkage when applied in cavities with adhesive resin (0.94-2.55) compared with those without $(2.01-3.45)(\mathrm{p}<0.05)$ and presented significantly more shrinkage after polymerisation $(\mathrm{p}<0.05)$. At a 2-mm cavity depth without $(2 \mathrm{~mm}, 2.28 ; 4 \mathrm{~mm}, 2.41)$ and with adhesive $(2 \mathrm{~mm}, 0.94 ; 4 \mathrm{~mm}, 1.67)$, significantly less shrinkage was observed with FB compared with SDR and TB $(\mathrm{p}<0.05)$. At a 4-mm cavity depth without (3.14) and with adhesive (2.55), SDR showed significantly higher shrinkage compared with FB and TB $(\mathrm{p}<0.05)$. CONCLUSIONS The bulk-fill composites tested presented less shrinkage when used in conjunction with adhesive resin application on dentin. Overall, the low-viscosity bulk-fill resin SDR showed more shrinkage compared with high-viscosity resins tested. CLINICAL RELEVANCE Low- or high-viscosity bulk-fill resin composites should be applied on dentin after application of adhesive resin to decrease shrinkage.
\end{abstract}

DOI: https://doi.org/10.1007/s00784-019-03025-5

Posted at the Zurich Open Repository and Archive, University of Zurich ZORA URL: https://doi.org/10.5167/uzh-197140

Journal Article

Accepted Version

Originally published at:

Ersen, Kadriye Aybüke; Gürbüz, Ȯzge; Ȯzcan, Mutlu (2020). Evaluation of polymerization shrinkage of bulk-fill resin composites using microcomputed tomography. Clinical Oral Investigations, 24(5):1687-1693.

DOI: https://doi.org/10.1007/s00784-019-03025-5 


\title{
Kadriye Aybüke Ersen ${ }^{1} \bullet$ Özge Gürbüz² $\bullet$ Mutlu Özcan ${ }^{3}$
}

\author{
${ }^{1}$ K.A. Ersen \\ Istanbul Medipol University, School of Dentistry, Department of Restorative Dentistry, Istanbul, Turkey \\ e-mail: aybikee@msn.com
}

20̈. Gürbüz

Istanbul Medipol University, School of Dentistry, Department of Restorative Dentistry, Istanbul, Turkey

${ }^{3} \mathrm{M}$. Özcan

University of Zürich, Dental Materials Unit, Center for Dental and Oral Medicine, Clinic for Fixed and Removable Prosthodontics and Dental Materials Science, Zürich, Switzerland

Short title: Polymerization shrinkage of bulk-fill resin composites

\section{Correspondence to:}

Dr. Kadriye Aybüke Ersen

Istanbul Medipol University

School of Dentistry

Department of Restorative Dentistry

Birlik Mah. Bahçeler Cad. No: 5, Esenler Medipol Hospital

Esenler 34230

İstanbul, Turkey

Tel: +90-212-440-10-00

E-mail: aybikee@msn.com

\section{Abstract}


Objectives: This study evaluated the influence of cavity depth on polymerization shrinkage of bulk-fill resin composites with and without adhesive resin.

Materials and Methods: Standardized box-shaped cavities (width: $4 \mathrm{~mm}$; length: $5 \mathrm{~mm}$, depth: $2 \mathrm{~mm}$ or $4 \mathrm{~mm}$ ) were made on occlusal surfaces of extracted human third molars $(\mathrm{N}=60)$. The teeth were assigned to 3 groups to receive bulk-fill resin composites (low viscosity bulk-fill: SDR, high viscosity bulk-fill: Filtek Bulk Fill-FB and

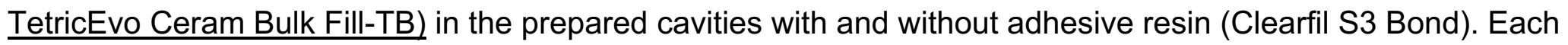
specimen ( $\mathrm{n}=5$ per group) was scanned twice using microcomputed tomography (micro-CT): once after application of the resin composite to the cavity prior to polymerization and once after polymerization. The shrinkage of volumetric loss (\%) was measured using micro-CT. Data were analysed using Kruskal-Wallis and Mann-Whitney U tests (alpha=0.05).

Results: The material type $(p<0.05)$, application of adhesive resin $(p<0.05)$ and cavity depth $(p<0.05)$ significantly affected the shrinkage values. The interaction terms were also significant $(p<0.05)$. All the bulk-fill resin composites tested showed significantly less shrinkage when applied in cavities with adhesive resin (0.942.55) compared with those without $(2.01-3.45)(p<0.05)$ and presented significantly more shrinkage after polymerization $(p<0.05)$. At a $2 \mathrm{~mm}$ cavity depth without $(2 \mathrm{~mm}: 2.28 ; 4 \mathrm{~mm}: 2.41)$ and with adhesive $(2 \mathrm{~mm}$ : 0.94; $4 \mathrm{~mm}: 1.67)$, significantly less shrinkage was observed with FB compared with SDR and TB ( $p<0.05)$. At a $4 \mathrm{~mm}$ cavity depth without (3.14) and with adhesive (2.55), SDR showed significantly higher shrinkage compared with FB and TB $(p<0.05)$.

Conclusions: The bulk-fill composites tested presented less shrinkage when used in conjunction with adhesive resin application on dentin. Overall, the low-viscosity bulk-fill resin SDR showed more shrinkage compared with high-viscosity resins tested.

Clinical Relevance: Low- or high-viscosity bulk-fill resin composites should be applied on dentin after application of an adhesive resin to decrease shrinkage. 
Keywords: Adhesion • Adhesive resin • Bulk-fill resin composite • Micro-CT • Polymerization shrinkage

Introduction 
In restorative dentistry, resin-based composite materials allow for minimum loss of tooth substance and offer maximum strength while retaining aesthetic and functional characteristics. In addition to such advantages, polymerisation shrinkage is the most significant problem associated with resin composites. As methacrylate monomers polymerize, van der Waals gaps become narrower due to covalent bonding, resulting in 1.5 to $5 \%$ volumetric contraction [1]. Configuration factor ( $\mathrm{C}$ factor), which is the ratio of the number of bonded to unbonded surfaces, markedly affects the extent and stress of shrinkage. Cavities with a higher $C$ factor and those with larger dimensions present increased polymerisation shrinkage [2].

Polymerisation shrinkage causes several complications, such as a disjunction at the tooth-composite interface [3], enamel cracks [4] and secondary caries. When using conventional resin composites, an incremental layering technique is advised to control the shrinkage, but this technique is time-consuming. Recently, to overcome this limitation, bulk-fill composites have been introduced [5]. The intention with such materials is to allow fabrication of 4 to $5 \mathrm{~mm}$ thick resin composite restoration in a single layer and thereby save time. Bulk-fill composites have low polymerisation shrinkage and are thus relatively more useful for patients and clinicians, as claimed by their manufacturers. However, there are not sufficient clinical studies on the use of these materials to date [6], particularly those focusing on the high $\mathrm{C}$ factor of cavities.

Since the early 1980s, computed tomography (CT) technologies have gained more importance in preclinical and clinical research. The first X-ray microtomography system was developed by Jim Elliot in the early 1980s, and the first published X-ray microcomputed tomography (micro-CT) images were reconstructed from slices of a small tropical snail with a cross-sectional thickness of approximately $50 \mu \mathrm{m}$ [7]. Since then, software and hardware features have been significantly improved, enabling clearer image acquisition at reduced crosssectional thicknesses [8] from approximately $7 \mathrm{~mm}$ thickness in conventional CT to $81 \mu \mathrm{m}$ [9], $34 \mu \mathrm{m}$ [10] and 12.5 [11] $\mu \mathrm{m}$ in micro-CT. Given the advances in micro-CT, faster acquisition of high-resolution 3D images has become possible even with small objects as it corrects the artefacts caused by air bubbles and provides accurate 
images regardless of the shape of the object and its position [12]. Today, micro-CT is also used for polymerisation shrinkage measurements with accurate results [13]. Micro-CT results could also enable a better understanding of polymerisation shrinkage stress with respect to the elasticity modulus of materials.

The objective of this study therefore was to investigate the influence of cavity depth and the use of adhesive resin on dentin on the polymerization shrinkage of bulk-fill resin composites using micro-CT. The null hypothesis tested was that there would be no significant difference in polymerisation shrinkage of bulk-fill materials at 2- or 4-mm cavity depths with and without use of the adhesive resin.

\section{Materials and methods}

\section{Tooth selection and cavity preparation}

Recently extracted human third molars $(\mathrm{N}=60)$ were collected after approval of the Ethical Committee of the Istanbul Medipol University, School of Dentistry. To confirm sample size, power analysis was conducted where $\Delta$ was 0.7 and standard deviation was 0.3 . Accordingly, the number of specimens determined for 0.80 power at $\underline{\alpha:} 0.05$ was $n=4$ for each subgroup.

The teeth with intercuspal width and mesiodistal length within a maximum deviation of $10 \%$ from their respective specific means (9.5-10.5 mm and 10.5-11.5 mm, respectively) were selected. All teeth were cleaned from hard and soft tissue debris using periodontal ultrasonic scalers (Woodpecker UDS-B, Guilin Woodpecker Medical Instrument Co., China) at $30 \mathrm{kHz}$ by one operator and were stored in distilled water at room temperature $\left(25^{\circ} \mathrm{C}\right)$ before and after cavity preparation.

Standardised box-shaped class I cavities were prepared paying attention that occlusal fissure acts as the midpoint of the width and positioned in the midst the cavity in the mesio-distal length of teeth (width: $4 \mathrm{~mm}$; length: $5 \mathrm{~mm}$ ). Half of the teeth received cavities with a depth of $2 \mathrm{~mm}$ and the other half $4 \mathrm{~mm}$. Cavities were prepared with round and fissure diamond dental burs (Kerr, California, USA) under water cooling by one 
researcher. Throughout cavity preparation, the dimensions were frequently assessed with a digital calliper with $0.01 \mathrm{~mm}$ sensitivity. Cavity depth was also controlled with a periodontal probe. One dental bur was used for preparing six consecutive cavities. Each cavity preparation took approximately 20 minutes.

\section{Restorative procedures}

The cavities were randomly assigned to 12 groups ( $n=5$ per group) according to the adhesion procedures and the filling materials used. In all groups, the cavities were filled with the bulk-fill composite assigned to their group. After adhesive resin (Clearfil S3 Bond, Kuraray Noritake Dental, Tokyo, Japan) application the cavities were restored with either high-viscosity bulk-fill composites (Filtek Bulk Fill-FB; 3 M ESPE, St. Paul, MN USA; Tetric EvoCeram Bulk Fill-TB; Ivoclar Vivadent AG, Liechtenstein) or low-viscosity bulk-fill composite (SDR; Dentsply, York, USA) depending on the assigned group (Table 1). Only Shade A2/U of each composite was used.

\section{Micro-CT imaging}

The teeth were kept in dark before photo-polymerization, and micro-CT scans were performed (Skyscan 1172, Bruker, Kontich, Belgium). Each tooth was scanned for approximately $30 \mathrm{~min}$. To ensure that the same amount of resin composite was applied to the cavities in all samples, aluminium reference moulds $\left(2 \times 4 \times 5 \mathrm{~mm}^{3}\right.$ and $\left(4 \times 4 \times 5 \mathrm{~mm}^{3}\right)$ were used for 2-mm and 4-mm deep cavities, respectively. After the first scan, each tooth was removed from the scanner using a sample holder and polymerised using an LED photo-polymerization device (BA Optima 10, B.A. International, Northampton, England). Each tooth was placed again in the micro-CT device for a second scan with a reference line over the platform to ensure that the scans are performed exactly from the same position of the tooth.

Each tooth was scanned before and after polymerisation and volumetric shrinkage was calculated. For photo polymerization, the distance between the light source and the bulk-fill composite was kept at $0.5 \mathrm{~mm}$ using a fixed device where the lamp was attached. The duration of polymerization was $20 \mathrm{~s}, 40 \mathrm{~s}$ and $10 \mathrm{~s}$ for SDR, TB and FB, respectively. 
Overall, 120 micro-CT readings were acquired from 60 scanned teeth. To ensure the stability of each tooth in the device and to maintain a constant distance between the X-ray source and the sample before and after polymerisation, teeth were embedded in silicon impression material (Zetaplus, Zhermack, Badia Polesine, Italy). It was also assured that the cemento-enamel junction (CEJ) was over the sample holder. Use of the mould for each sample restricted positional changes while repeating the micro-CT scanning as described earlier [13]. The operating energy (100 Kvp, 100 microampers), resolution $(16.06 \mu \mathrm{m} / \mathrm{slice})$ and rotation step (0.5 degree) for the micro-CT device were kept constant for all samples. The acquired raw images were reconstructed with the software (SkyScan reconstruction program, NRecon, v.1.6.9.4, Bruker) to correct for radiologic artefacts and prepared for analysis. Images were converted to $1000 \times 1000$ pixel resolution in *.bmp format. Then, the reconstructed images were analysed using the determined processes in the software (Skyscan software CTAn, v. 1.15.4.0, Bruker) according to the following workflow: raw image acquisition, identification of region of interest, binary selection, morphometry and custom processing (Figs. 1a-b). From these data, volumetric loss due to polymerisation shrinkage was calculated as a percentage.

\section{Statistical analysis}

Statistical analysis was performed using Number Cruncher Statistical System 2007 Statistical Software (Utah, USA). Data were expressed as the mean, standard deviation, median, frequency, percentage, minimum, and maximum values. Kolmogorov-Smirnov and Shapiro-Wilk tests were used to test normal distribution of the data. As the data were not normally distributed, Kruskal-Wallis test was used for comparisons of parameters, and Mann-Whitney $U$ and Wilcoxon tests were used for pairwise comparisons. A $p$-value of $<0.05$ was considered statistically significant in all tests.

\section{Results}


Material type $(p<0.05)$, application of adhesive resin $(p<0.05)$ and cavity depth $(p<0.05)$ significantly affected the shrinkage values. Interaction terms were also significant $(p<0.05)$.

All bulk-fill resin composites tested showed significantly less shrinkage when applied in the cavities with adhesive resin $(0.94-2.55)$ compared with those without $(2.01-3.45)(p<0.05)$ and presented significantly more shrinkage after polymerization $(p<0.05)($ Table 2$)$.

For all materials tested, volumetric shrinkage after polymerisation was significantly increased compared with the non-polymerized stage $(p=0.001)$. At $2-\mathrm{mm}$ cavity depth without $(2 \mathrm{~mm}: 2.28 ; 4 \mathrm{~mm}: 2.41)$ and with adhesive (2 mm: 0.94; $4 \mathrm{~mm}$ : 1.67), significantly less shrinkage was observed with FB compared with SDR and TB $(p<0.05)$. At 4-mm cavity depth without (3.14) and with adhesive (2.55), SDR showed significantly increased shrinkage compared with FB and TB $(p<0.05)$.

When adhesive resin was applied, specimens with $4 \mathrm{~mm}$ deep cavities showed higher volumetric loss compared with $2 \mathrm{~mm}$ deep cavities. Volumetric loss was significantly higher in SDR and FB than with TB. Representative micro-CT images are presented in Figs. 2a-d.

\section{Discussion}

This study assessed the influence of cavity depth and the use of adhesive resin on dentin on the polymerization shrinkage of bulk-fill resin composites using micro-CT. Since the material type, application of adhesive resin and cavity depth significantly affected the shrinkage values, the null hypothesis was partially rejected.

Use of bulk-fill composites allows for reduced application steps during incremental build-up of resin composites in the cavities, thus reducing a clinician's operational errors and chairside time. Application of self-etch adhesives also further eases the implementation of bulk-fill composites. However, herein, concerns are present regarding the polymerisation shrinkage severity and shrinkage stress of bulk-fill composites $[14,15]$. Typically, for many resin composites, a linear relationship is reported between the polymerisation shrinkage and the associated 
polymerisation shrinkage stress [16]. Similarly, a direct correlation among polymerisation stress, shrinkage and marginal gap has been previously reported $[17,18]$. In this regard, using micro-CT, the consistency of bulk-fill composites applied to class II cavities was demonstrated to affect the internal gap and polymerisation shrinkage where the flowable bulk-fill resin showed less favourable results [19]. Certainly cavity configuration (C factor), restoration volume, restoration technique significantly affects the polymerization stress $[20,21]$. For instance, cavities with higher $C$ factor have inferior mechanical characteristics due to the higher shrinkage stress [22].

In this study, all bulk-fill resin composites showed shrinkage, and this finding varied depending on the product as volumetric loss was significantly higher in SDR and FB compared with TB. The reason for favourable results with TB could be explained by its chemical composition. Moszner et al. investigated the use of benzoyl germanium derivatives as a novel visible photo initiator and compared these results with other photoinitiators based on benzoyltrimethylgermane (BTMGe) or dibenzoyldiethylgermane (DBDEGe) that are mixed with camphorquinone (CQ) and ethyl 4- (N,N-dimethylamino)benzoate (EMBO) [23]. Accordingly, photo initiators based on BTMGe and DBDEGe showed significantly more intense absorption in the visible region compared with CQ. In our study, TB with the germanium-based initiator showed the lowest polymerisation shrinkage in 4$\underline{\mathrm{mm} \text { deep cavities although the time of exposure to light was the least among all tested bulk-fill composites. }}$ Increased extent of polymerisation with bulk-fill composites is obtained with the modulation of translucency and photo initiators. Moszner et al. reported that the germanium-based Ivocerin initiator in Tetric EvoCeram Bulk Fill exhibits increased light activation than camphorquinone [16]. A new germanium-based photoinitiator has been accepted as a pre-polymer stress reliever that putatively decreases polymerisation shrinkage and stress [23]. While polymerising resin composites, the tip of light source was positioned $0.5 \mathrm{~mm}$ distant to the resin composite surface [24].

Even if an adhesive is not used, resin composites could hold to the cavity surface due to surface irregularity; in unbonded groups, the shrinkage pattern was not regular [25]. In our study, volumetric loss (\%) was significantly 
increased in unbonded samples compared with bonded samples. This result shows that the use of an adhesive significantly reduced the volumetric shrinkage. On examining shrinkage using micro-CT with and without an adhesive resin, Algamaiah et al. showed that the adhesive application in combination with different bulk-fill composites reduces polymerisation shrinkage by approximately $13 \%$ [26]. The values obtained in this study were considerably less. However, from clinical perspective, application of adhesive resin adds to the time spent also for the bulk-fill composites.

$\underline{\text { In all situations except in unbonded samples with a } 2 \mathrm{~mm} \text { depth, SDR showed higher polymerisation shrinkage }}$ than other resin composites. The results of this observation are consistent with that of Algamaiah et al. [26] where SDR showed the highest percentage in shrinkage among all tested materials (Tetric EvoCeram Bulk Fill, and Filtek flowable Bulk Fill) (3.65\% and $3.78 \%$, respectively).

Given its three-dimensional imaging capabilities, micro-CT is a preferred method to measure polymerisation shrinkage in cavities [25]. The accuracy of this method also allows for visualisation of failures, such as air bubbles, which cannot be rendered by conventional methods, such as replica techniques [12]. An important limitation of micro-CT is noted with analysing materials with low fillers or those that do not have sufficient radiopacity, such as certain dental adhesives [25,27]. Both enamel and resin composites highly scatter light. Thus, differentiating between the two and setting a threshold is more challenging and potentially causes uncertainty. Although scanning in micro-CT was performed in fixed positions and images of samples were arranged using fiducial markers or reference locations in each sample, the images may not completely overlap during measurements before and after polymerization [28]. This is one limitation of this study. Nevertheless, in contrast to sectioning procedures that inherently damage specimens, micro-CT is a non-destructive 3D imaging method. Given its three-dimensional imaging capabilities, micro-CT is the preferred device to measure polymerisation shrinkage in cavities [25]. The accuracy of this method allows us to visualise failures as bubbles, which cannot be rendered by conventional methods, such as replica techniques [12]. The results of this study 
should be verified in larger samples, and different cavity dimensions should be correlated with shrinkage potential of the bulk-fill materials in future studies.

Resin composites with high filler loads have less monomers and thus less polymerisation shrinkage. Although filler particle space does not participate in polymerization contraction, high filler loads require low-molecular weight monomers to ensure proper viscosity for handling. Conversely, in lower viscosity materials, monomers move actively given their increased participation in increasing polymerisation shrinkage [29]. In this study, the $\underline{\text { SDR group presented significantly higher volumetric loss than FB and TB. As a result, it could be stated that }}$ low-viscosity bulk-fill composites show higher polymerisation shrinkage than high viscosity bulk composite. When comparing shrinkage amounts according to the cavity depth, 4-mm deep cavities showed more shrinkage compared with 2-mm deep cavities in most groups, thus indicating that bulk-fill composites currently have an acceptable shrinkage range, but further improvements are still needed for larger and deeper cavities.

\section{Conclusions}

From this study, the follow could be concluded:

1) All tested bulk-fill resin composites tested showed polymerisation shrinkage at varying degrees depending on the product.

2) Increased cavity depth from 2 to $4 \mathrm{~mm}$ increased shrinkage and volumetric loss in all materials tested except for FB.

3) Application of adhesive resin decreased volumetric loss, but samples with and without adhesive SDR showed significantly higher volumetric loss compared with other bulk-fill materials. 


\section{Compliance with ethical standards}

Conflict of Interest: The authors declare that they have no conflict of interest.

Funding: The work was supported by TUBITAK (Grant number: 215S840), Turkey.

Ethical Approval: This article does not contain any studies with human participants or animals.

Informed Consent: Formal consent is not required for this type of study. 


\section{References}

1. Bouillaguet S, Gamba J, Forchelet J, Krejci I, Wataha JC (2006) Dynamics of composite polymerization mediates the development of cuspal strain. Dent Mater 22:896-902

2. Silikas N, Eliades G, Watts DC (2000) Light intensity effects on resin-composite degree of conversion and shrinkage strain. Dent Mater 16:292-296

3. Krejci I, Planinic M, Stavridakis M, Bouillaguet S (2005) Resin composite shrinkage and marginal adaptation with different pulse-delay light curing protocols. Eur J Oral Sci 113:531-536 4. Panduric V, Demoli N, Tarle Z, Sariri K, Mandic VN, Knezevic A, Sutalo J (2007) Visualization of Marginal Integrity of Resin-Enamel Interface by Holographic Interferometry. Oper Dent $32: 266-272$

5. Tsujimoto A, Barkmeier WW, Takamizava T, Latta MA, Miyazaki M (2017) Depth of cure, flexural properties and volumetric shrinkage of low and high viskosity bulk-fill giomers and resin composites. Dent Mater 36:205-213

6. Walter R (2013) Bulk-Fill Flowable Composite Resins. J Esth Res Dent 25:72-76

7. Elliot JC, Dover SD (1982) X-ray microtomography. J Microsc 126:211-213

8. Gambill JM, Alder M, del Rio CE (1996) Comparison of nickel-titanium and stainless steel hand-file instrumentation using computed tomography. J Endod 22:369-375

9. Rhodes JS, Ford TR, Lynch JA, Liepins PJ, Curtis RV (1999) Microcomputed tomography: a new tool for experimental endodontology. Int Endod J 32:165-170

10. Kuhn JL, Goldstein SA, Feldkamp LA, Goulet RW, Jesion G (1990) Evaluation of a microcomputed tomography system to study trabecular bone structure. J Orthop Res 8:833-842 
11. Bergmans L, Van Cleynenbreugel J, Beullens M, Wevers M, Van Meerbeek B, Lambrechts P (2003) Progressive versus constant tapered shaft design using NiTi rotary instruments. Int Endod J 36:288-295

12. Sun J, Lin-Gibson S (2008) X-ray microcomputed tomography for measuring polymerization shrinkage of polymeric dental composites. Dent Mater 24:228-234

13. Kim HJ, Park SH (2014) Measurement of the internal adaptation of resin composites using micro-ct and its correlation with polymerization shrinkage. Oper Dent 39:57-716.

14. Ilie N, Bucuta S, Draenert M (2013) Bulk-fill resin-based composites: an in vitro assessment of their mechanical performance. Oper Dent 38:618-25

15. Leprince JG, Palin WM, Vanacker J, Sabbagh J, Devaux J, Leloup G (2014) Physicomechanical characteristics of commercially available bulk-fill composites. J Dent 42:993-1000 16. Kleverlaan CJ, Feilzer AJ (2005) Polymerization shrinkage and contraction stress of dental resin composites. Dent Mater 21:1150-1157

17. Ferracane JL, Mitchem JC (2003) Relationship between composite contraction stress and leakage in Class V cavities. Am J Dent 16:239-243

18. Calheiros FC, Sadek FT, Braga RR, Cardoso PE (2004) Polymerization contraction stress of low-shrinkage composites and its correlation with microleakage in Class $V$ restorations. J Dent $32: 407-412$

19. Han SH, Park SH (2017) Comparison of Internal Adaptation in Class II Bulk-fill Composite Restorations Using Micro-CT. Oper Dent 42:203-214

20. Gordan VV, Mjor IA (2002) Short- and long-term clinical evaluation of postoperative sensitivity of a new resin-based restorative material and self-etching primer. Oper Dent 27:543548 
21. Ilie N, Hickel R (2009) Investigations on mechanical behavior of dental composites. Clin Oral Invest 13:427-438

22. Cho E, Sadr A, Inai N, Tagami J (2011) Evaluation of resincomposite polymerization by three dimensional micro-CT imaging and nanoindentation. Dent Mater 27:1070-1078

23. Moszner N, Fischer UK, Ganster B, Liska R, Rheinberger V (2008) Benzoyl germanium derivatives as novel visible light photoinitiators for dental materials. Dent Mater 24:901-907

24. Fronza BM, Rueggeberg FA, Braga RR, Mogilevych B, Soares LES, Martin AA, Ambrosano G, Giannini M (2015) Monomer conversion, microhardness, internal marginal adaptation, and shrinkage stress of bulk-fill resin composites. Dent Mater 31:1542-1551

25. Chiang YC, Röschb P, Dabanoglu A, Linc CP, Hickel R, Kunzelmanna KH (2010) Polymerization composite shrinkage evaluation with 3D deformation analysis from CT images. Dent Mater 26:223-231

26. Algamaiah H, Sampaio CS, Rigo LC, Janal MN, Giannini M, Bonfante EA, Coelho PG, Reis AF, Hirata R. (2017) microcomputed tomography evaluation of volumetric shrinkage of bulk-fill composites in class ii cavities. J Esthet Restor Dent 29:118-127

27. Papadogiannis D, Kakaboura A, Palaghias G, Eliades G (2009) Setting characteristics and cavity adaptation of low-shrinkage resin composites. Dent Mater 25:1509-1516

28. Zeiger DN, Sun J, Schumacher GE, Lin-Gibson S (2009) Evaluation of dental composite shrinkage and leakage in extracted teeth using X-ray microcomputed tomography. Dent Mater 25:1213-1220

29. Davidson CL, Feilzer AJ (1997) Polymerization shrinkage and polymerization shrinkage stress in polymer based restoratives. J Dent 25:435-440 


\section{Figure and table captions:}

\section{Tables:}

Table 1. Brands, manufacturers, types, chemical compositions and batch numbers of the tested materials. MDP: 10-methacryloyloxydecyl dihydrogen phosphate, HEMA: 2-hydroxyethyl methacrylate Bis-GMA: bisphenol-A diglycidyl ether dimethacrylate, TEGDMA: triethylene glycol dimethacrylate.

Table 2 Polymerisation shrinkage values reported as percentage with and without adhesive in 2 and $4 \mathrm{~mm}$ deep cavities.

\section{Figures:}

Figures 1a-b. a) Operation of region of interest (ROI) constitution, b) Operation of binary selection in CTAn analysis programme.

Figures 2a-d. Representative micro-CT images of horizontal sectional views from the SDR grol a) Before-polymerisation, b) after-polymerisation, c) magnified view of the relevant regi polymerisation, d) magnified view of the relevant region after polymerisation. Note that the resin is viewed in white, dentin in black, and enamel in grey. Shrinkage can typically be observed in sections where the red arrows indicate increased marginal gap between the composite and the tooth. 


\section{Tables}

Table 1 Brands, mnaufactures, types, chemical compositions and batch numbers of the tested materials

\begin{tabular}{|c|c|c|c|c|}
\hline Brand & Manufacturer & Type of Material & Content & Lot numbe \\
\hline SDR & Dentsply, USA & $\begin{array}{l}\text { Low viscosity } \\
\text { bulk-fill composite }\end{array}$ & $\begin{array}{l}\text { TEGDMA, } \\
\text { EBADMA, weight } \\
68 \% \text {, volume } 44 \% \text {, } \\
\text { barium borosilicate } \\
\text { glass }\end{array}$ & 150800070 \\
\hline Filtek Bulk Fill & $\begin{array}{l}\text { 3M/ESPE, St. Paul, } \\
\text { MN, USA }\end{array}$ & $\begin{array}{l}\text { High viscosity } \\
\text { bulk-fill composite }\end{array}$ & $\begin{array}{l}\text { Bis-GMA, bis-EMA, } \\
\text { UDMA, zircon } \\
\text { weight } 64 \% \text {, volume } \\
42 \%\end{array}$ & U17294 \\
\hline $\begin{array}{l}\text { Tetric EvoCeram } \\
\text { Bulk Fill }\end{array}$ & $\begin{array}{l}\text { Ivoclar Vivadent } \\
\text { AG, Liechtenstein }\end{array}$ & $\begin{array}{l}\text { High viscosity } \\
\text { bulk-fill composite }\end{array}$ & $\begin{array}{l}\text { Barium glass weight } \\
80 \% \text {, volume } 60 \% \text {, } \\
\text { dimethacrylate co- } \\
\text { monomers }\end{array}$ & N708090 \\
\hline Clearfil S3Bond & $\begin{array}{l}\text { Kuraray Noritake } \\
\text { Dental Inc., Tokyo, } \\
\text { Japan }\end{array}$ & Self-etch adhesive & $\begin{array}{l}\text { MDP, HEMA, bis- } \\
\text { GMA, hydrophobic } \\
\text { dimetacrylate, ethyl } \\
\text { alcohol, water, } \\
\text { photoinitiators, } \\
\text { colloidal silica }\end{array}$ & 2R0027 \\
\hline
\end{tabular}

$\overline{M D P}$ 10-methacryloyloxydecyl dihydrogen phosphate, HEMA 2-hydroxyethyl methacrylate Bis-GMA bisphenol-A diglycidyl ether dimethacrylate, 4-MET 4-methacryloyloxyethyltrimellitic acid, TEGDMA triethylene glycol dimethacrylate. 
Table 2 Polymerisation shrinkage values reported as percentage of determined groups with and without adhesive in $2 \mathrm{~mm}$ and $4 \mathrm{~mm}$ depth

\begin{tabular}{|c|c|c|c|c|}
\hline Resin composite & $\begin{array}{l}\text { Without Adhesive } \\
\qquad(2 \mathrm{~mm})\end{array}$ & $\begin{array}{l}\text { With Adhesive W } \\
(2 \mathrm{~mm})\end{array}$ & $\begin{array}{l}\text { Without Adhesive } \\
\qquad(4 \mathrm{~mm})\end{array}$ & $\begin{array}{l}\text { With Adhesive } \\
\qquad(4 \mathrm{~mm})\end{array}$ \\
\hline \multicolumn{5}{|c|}{ Mean (SD) } \\
\hline SDR & $3.45(3.15)$ & $1.75(1.96)$ & $3.14(3.27)$ & $2.55(2.56)$ \\
\hline Filtek Bulk Fill & $2.28(2.6)$ & $0.94(1.05)$ & $2.41(2.62)$ & $1.67(1.63)$ \\
\hline Tetric EvoCeram Bulk Fill & $3.9(2.38)$ & $1.45(1.66)$ & $2.01(1.95)$ & $1.65(1.78)$ \\
\hline
\end{tabular}




\section{Figure 1:}

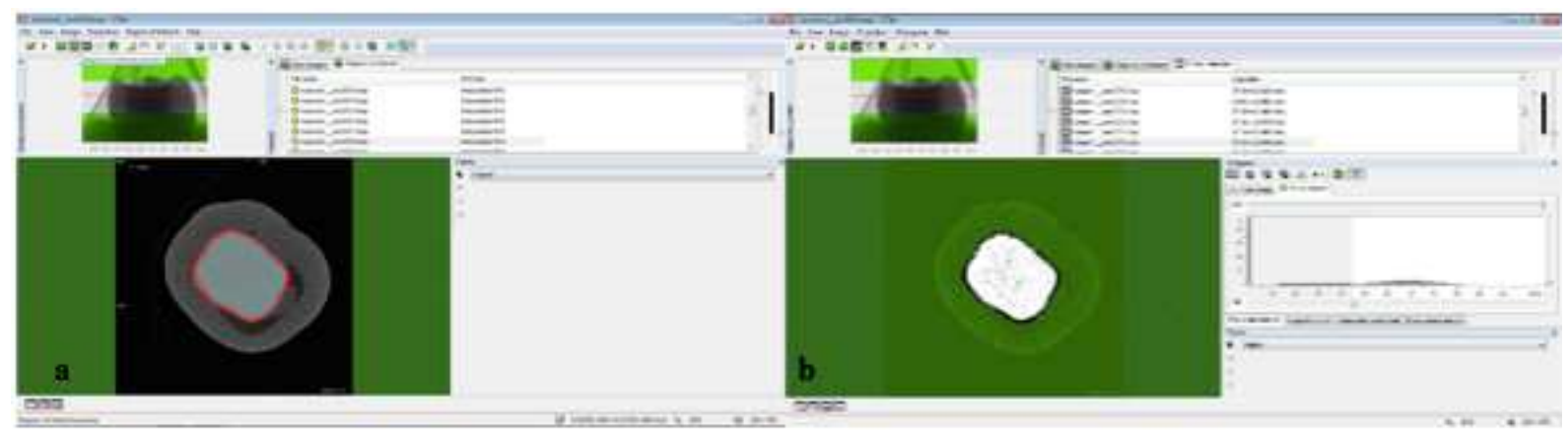

Figures 1a-b. a) Operation of region of interest (ROI) constitution, b) Operation of binary selection in CTAn analysis programme. 


\section{Figure 2:}

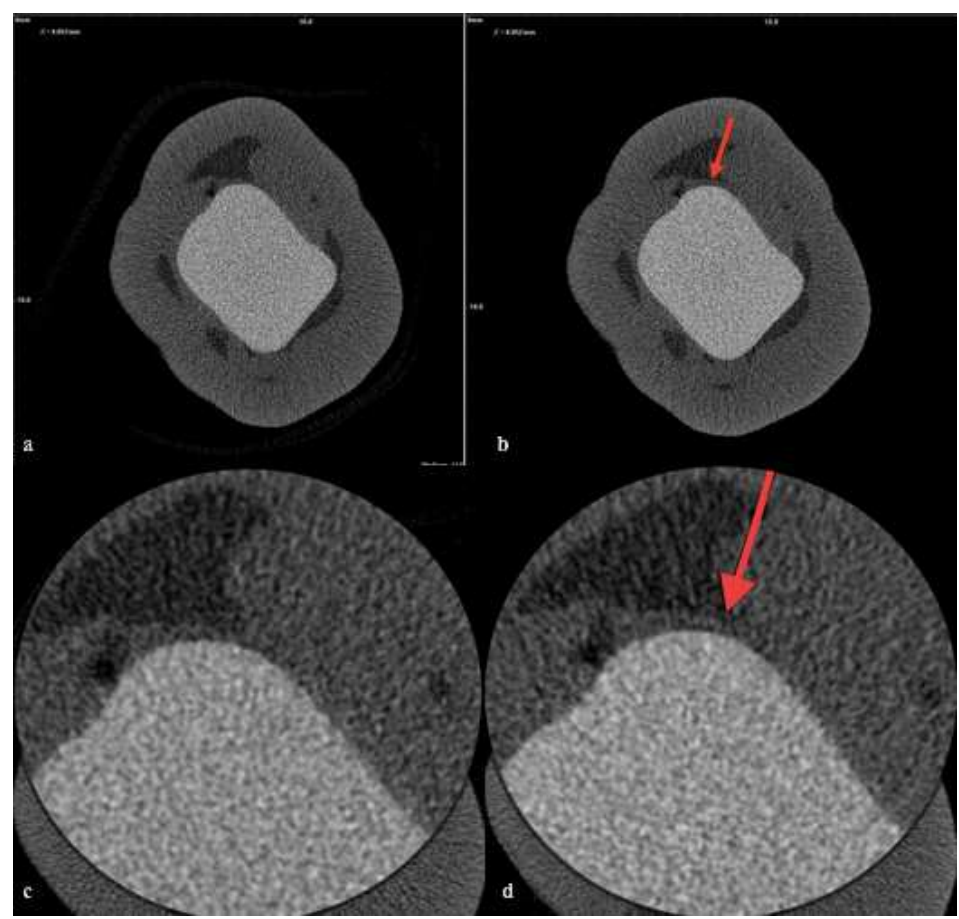

Figures 2a-d. Representative micro-CT images of horizontal sectional views from group SDR a) Beforepolymerisation, b) after-polymerisation, c) magnified view of the relevant region before polymerisation, $\mathbf{d}$ ) magnified view of the relevant region after polymerisation. Note that the resin composite is viewed in white, dentin in black, enamel in grey. Shrinkage can typically be observed in sections where the red arrows indicate increased marginal gap between the composite and the tooth. 
